\title{
STUDENT VIEWS OF TECHNOLOGY-MEDIATED WRITTEN CORRECTIVE FEEDBACK
}

\author{
Hanne Wacher Kjaergaard ${ }^{1}$ \\ ${ }^{1}$ Aarhus University (DENMARK)
}

\begin{abstract}
This article reports on the preliminary findings of an investigation of student beliefs, attitudes, and practices in relation to written corrective feedback in the context of the teaching of English in lowersecondary education in Denmark. The study is related to an intervention study carried out in three 8thgrades involving three teachers, introducing technology as the mediating tool for feedback. Results show a positive perceived impact of the intervention among the students.
\end{abstract}

Keywords: Language learning, feedback, technology, intervention, student cognitions.

\section{INTRODUCTION}

Writing and receiving feedback on one's writing are important activities in the learning of a foreign language as it allows the learners time to focus on the form of their language production and since written language is more permanent than spoken [1], [2]. Danish schools are generally technology-rich [3], but one area where technology use seems to have been taken over sparingly is the area of written corrective feedback (WCF) in language teaching and learning. This was shown in a survey of close to 300 Danish teachers of English as a foreign language [4]. Results from the survey showed that although a majority of teachers received their students' written assignments electronically, $54 \%$ still printed the students' papers and provided feedback on the hard copies. Working this way, it would seem that teachers deprive themselves and their students of some of the advantages that different forms of technology can provide them with in their work with teaching and learning a foreign language (see e.g. Kjaergaard [4]).

The present article reports on one part of an intervention study investigating

1. the potential changes in teacher beliefs and practices concerning the specific - and timeconsuming - language-teacher activity of providing WCF and

2. potential changes in student attitudes when technology is used to mediate the feedback.

After this brief introduction, section 2 introduces the background and context of the study. Next, the methodology used is briefly described in section 3 , and following this, in section 4 , I present the results characterizing the students' baseline beliefs and practices. In section 5 , developments during the intervention period are traced and discussed. Conclusions are presented in section 6 .

\section{BACKGROUND, CONTEXT, AND TECHNOLOGY}

At the core of the study is an eight-month intervention which was carried out with three teachers of English as a foreign language and their three lower-secondary classes. In the intervention, the teachers were required to make use of technology to provide their students with written corrective feedback, and students were to revise their work on the basis of the feedback they received. However, not any technology could be used; a specific program was selected by the researcher from a shortlist of programs.

\subsection{Technology}

Although major advances have been made in the field of automated written corrective feedback [5]-[7], there are two reasons why programs providing automated feedback were not included for selection: First, it would not be a realistic option for the teachers and students in this specific context: Students only hand in 5-6 assignments during a school year, they are young (8th grade = appr. 14 years of age), and they have a limited amount of explicit grammatical knowledge having learned English for 5 years 3 lessons/week. Second, it has been a "finding, in more than one study, [...] that the strongest effect was 
not between a CALL ${ }^{1}$-only condition and a traditional classroom condition, but from instruction combining the two" [8, p. 24].

Additionally, video-based feedback, very much propagated by e.g. Russell Stannard [9]-[14] in the form of screencasts, i.e. "digital recordings of the activity on one's computer screen, accompanied by voiceover narration" [15], was left out. There has been evidence that students may find this type of multimodal feedback more personal and hence motivational [11]-[13], [15]-[17], and teachers have also been reported to find this form of feedback both more personal [13], [17], [18] and time-saving [18], [19]. However, there are various drawbacks, especially if this mode of feedback is used on its own. These drawbacks led to the exclusion of this form of feedback: First, its use and effect has mainly been investigated in tertiary education, not necessarily in foreign-language learning contexts. Second, the spoken word is less 'permanent', more fleeting and momentary and more difficult to skim than its written counterpart [20], despite the possibility for students to pause, rewind, and watch again [12], [15], [21]. This makes it more difficult to get a systematic overview [12], [15], [21], let alone statistics, concerning one's language development. Third, it seems that video feedback can be more difficult for lower-level students to follow - perhaps due to the potential 'overload' caused by the ease with which the teacher can speak his/her feedback [22].

Finally, only dedicated programs were included on the shortlist. This means that generic word processing programs (e.g. MSWord, Google Docs, OpenOffice) were left out. Although some of these, especially the online tools, allow for cooperation, collaborative writing and peer feedback, these ways of working were not an option in the classrooms involved. Furthermore, programs built to specifically serve (professional, office) writing purposes lack some of the affordances that one would expect from dedicated programs as listed below.

This, then, meant that only dedicated feedback programs assisting teachers in providing text-based written corrective feedback were included on the shortlist of programs supportive of effective written corrective feedback. Programs on the shortlist included KungFu Writing [23], LangCorr [24], Grademark [25], Markin [26], and EasyCorrect [27], and the parameters for selection, resulting in the choice of Markin, pertained to:

- Language learning theory (e.g. the possibility for the teacher to highlight selected errors, a practice called indirect, selective feedback [28], [29], to provide corrections, known as direct feedback [28], [30], and to use metalinguistic language or codes [31]-[33], affording a problemsolving approach [34]).

- Adaptability (contextualization and individualization possible to make the program suit teacher, students, setting, materials).

- Usability (e.g. easy access, a flat learning curve for student and teacher, intuitive, easy overview, color coding, not visually overwhelming [35], exemplary templates as support for the teacher's adaptation).

- Availability of statistics (learning analytics allowing both teacher and student to have overview of development - across several papers or across whole cohort of students).

- Interactivity (engaging students as active in their own learning process) [36], [37].

\subsection{Program description}

Markin is quite a simple program that allows teachers to build their own little database of comments, which is then made into a set of buttons for easy use in the grading of papers. Behind each of the buttons there are three levels of help for the student: 1) the abbreviation to be used as button text by the teacher in his/her work (e.g. 'Punc'); 2) category of mistake as a hint to the students (e.g. 'punctuation', 'tense', or 'subject-verb agreement'; 3 ) an explanation, a link - some kind of more explicit help for the student to be able to self-correct the error (e.g. 'You need a comma between two main clauses'). The teacher's workspace is illustrated below in Fig. 1:

\footnotetext{
${ }^{1} \mathrm{CALL}=$ Computer-Assisted Language Learning.
} 


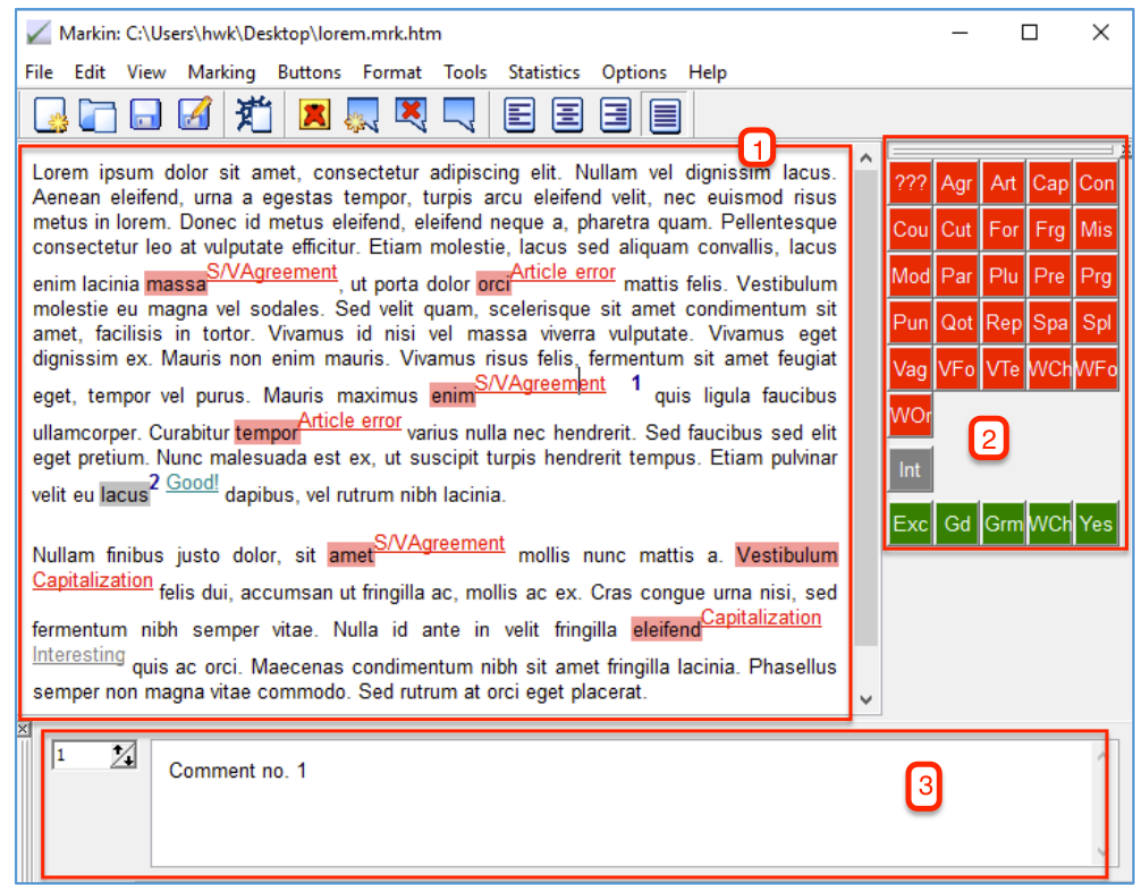

Figure 1: Teacher's work interface in Markin.

The main part of the window, marked 1 , holds the student's text, and by highlighting a section and clicking a button in the button area, marked 2, an annotation is inserted. Notice that annotations can be positive (green) neutral (gray), or negative (red) $)^{2}$. Additionally, free text comments can be inserted in the area marked 3. These will appear as small blue numerals in the student text area. Also a general, overall comment can also be given. The teacher can get an overview of errors by checking statistics (not visible in the figure). In many ways, the program thus supports the teacher in working systematically, using recognizable and 'stable' error categories, and allowing for a statistically-based overview of each student's error types. This should help the teacher provide more informed feedback and e.g. grammar teaching.

When the papers are returned to the students, the Markin file is converted to a clickable html file. Initially, the students are only shown the colored highlights, no annotations. A highlight may be enough to allow them to self-correct if their interlanguage and command of the language is at a stage where it just needs a little prompt to allow them to get closer to aligning their internal representation of the language, their interlanguage, to the target language. Alternatively, they click the highlight and are shown the category, this perhaps allowing them to rectify the error. If not, they click the category to reveal the more detailed explanation, link, or reference which is the highest degree of help they can get. The student interface is illustrated in Figs. 2 \& 3 :

\footnotetext{
${ }^{2}$ The color scheme is fully adjustable.
} 


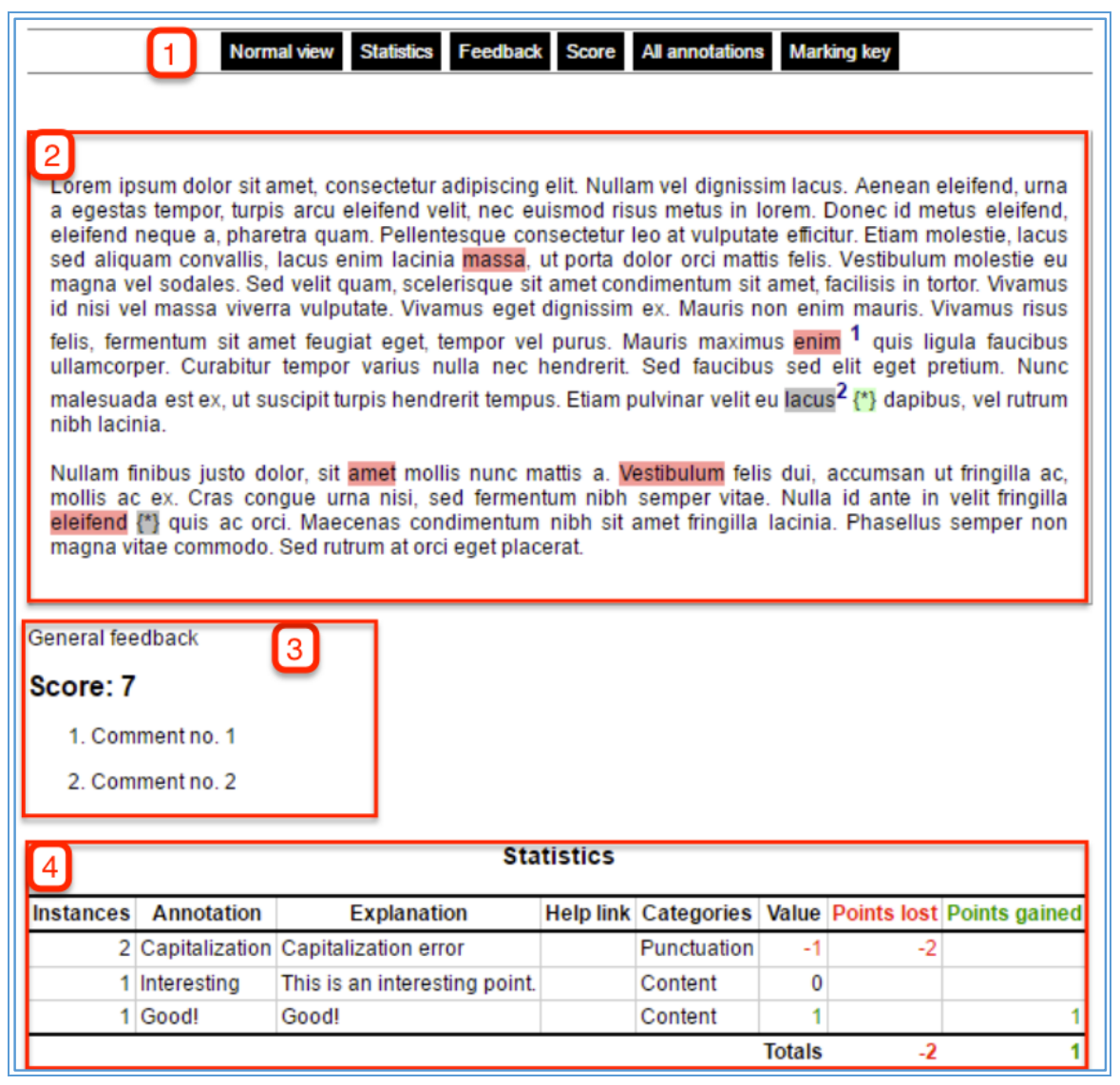

Figure 2: Student interface. 1: Menu; 2. Main text section with highlights;

3: Area for general teacher comment and free text comments; 4: Statistics overview.

\begin{tabular}{|l|l||}
\hline $\begin{array}{l}\text { lacus. Aenean eleifend, } \\
\text { lorem. Donec id metus } \\
\text { vulputate efficitur. Etiam } \\
\text { or orci Article error mattis } \\
\text { sit amet condimentum sit } \\
\text { get dignissim ex. Mauris } \\
\text { el purus. Mauris maximus } \\
\text { ndrerit Sed faurihus sed }\end{array}$ & $\begin{array}{l}\text { Do not use the definite article for something } \\
\text { that has not been introduced yet. Check your } \\
\text { grammar book p. XX and do the exercise here: }\end{array}$ \\
\hline
\end{tabular}

Figure 3: Illustration of comment clicked to show all three levels of feedback help: highlight, category, and explanation.

This program thus meets many of the requirements that can be made on the basis of what we know from research in the field of second and foreign language acquisition, e.g. indirect, metalinguistically coded feedback, statistics to help the student and teacher to follow progress, and it can help the student get involved through the interactivity and self-differentiation, through which the student can choose the amount of help necessary. The program can assist the teacher in working systematically on giving feedback attuned to the needs of the individual student

\section{METHODOLOGY}

Having thus set the scene and introduced the tool to be used, we can now move on to the specific part of the overall study to be reported on here, namely results pertaining to student attitudes to the changes brought about by the intervention. This part of the study involves a baseline and an endline questionnaire $(n=62)$ with many opportunities for free text answers and baseline and endline focus group interviews with four students per class. The study is thus a mixed-methods study. The qualitative data (interview and free text answers) were employed to provide a deeper insight into and understand student attitudes and potential changes in them, I employ these to shed more detailed light on the more standardized, numerical data from the questionnaires. 


\section{RESULTS - STUDENT BASELINE}

First, a brief characterization of student practices at the beginning of the project:

The majority (53 \%) spend over an hour per month doing written assignments for English, $34 \%$ spending 30-60 minutes, the remainder 15-30 minutes $^{3}$.

$90 \%$ of the students say they experience writing and getting feedback as activities that contribute to their learning, and the vast majority $(75 \%)$ provide free-text answers which indicate that feedback provides them with a focus for improvement in the next paper. Interestingly, however, $54 \%$ say they never or hardly ever look at their old assignments to check up on language points to be wary of with only $7 \%$ doing so every time or almost every time and $40 \%$ doing it "sometimes".

$72 \%$ say they have not been informed about the teacher's strategy in providing them with feedback. They generally find that their teacher sometimes highlights their mistakes and sometimes actually corrects the mistakes for them.

For the majority, the follow-up activity upon a paper being given back to them with feedback consists in the teacher going over common mistakes with the whole class, often giving students time to work on their mistakes in class. Only a few $(10 \%)$ say that they are expected to go home and correct the mistakes. Many of the students (48 \%) claim to just look at their returned paper in class, doing no other work on it, often throwing it away afterwards. This is also reflected in the amount of time they spend on follow-up activities as illustrated in Fig.4, which shows that almost half of the students spend less than 15 minutes on their returned work:

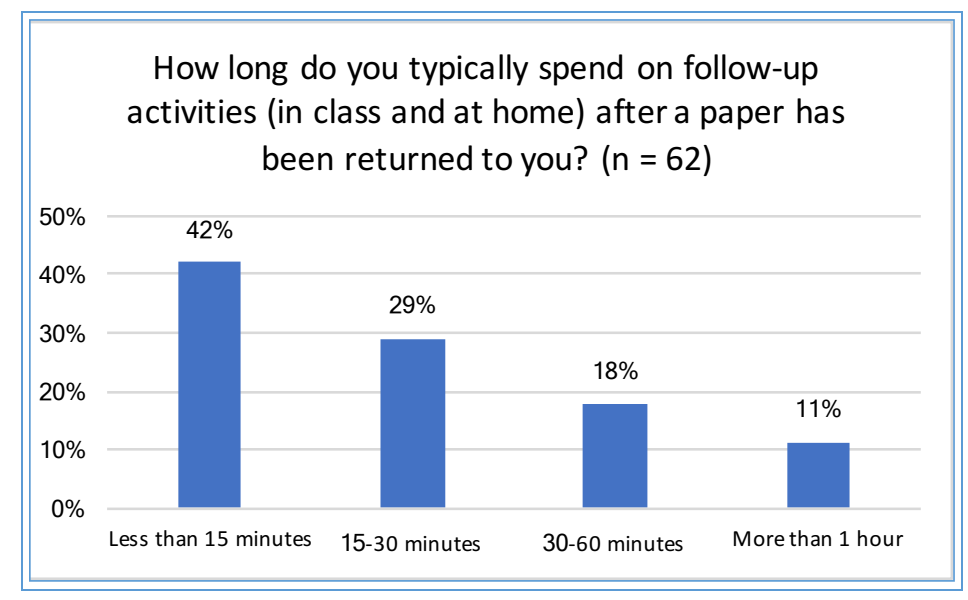

Figure 4: Student time spent on follow-up on feedback.

Paradoxically, despite many of them thus spending relatively little time on follow-up activities, students have great confidence that their teacher's feedback and corrections help improve their language skills: $77 \%$ believe that it helps them to some (50\%) or a very high $(27 \%)$ degree. $19 \%$ are in doubt, and 3 $\%$ believe the teacher's feedback to be of no help at all.

Asked whether they use grammar books or other reference material in following up on teacher feedback, only $24 \%$ report doing so every time or almost every time, while $34 \%$ never or hardly ever do.

$90 \%$ say they understand all (13\%) or most (77 \%) of their teacher's corrections and comments.

\subsection{Tools used}

When the students write their papers, they do it using technology - but they do not necessarily use word processors like MS Word or OpenOffice. Many of them say they use Google Docs, also because that it part of their school's offer to them, but they also use their phones, e.g. using Facebook Messenger or a notes program. They are not particularly skilled at using the built-in tools that can help them such as spell and grammar check or synonym assistance. They use the online bilingual (Danish-English) dictionary provided to them by the school, and they use Google searches both to find information on the topic of a given paper and to find images or YouTube videos showing how to conjugate verbs etc. if that information is not available from the dictionary. They report that they hardly ever use reference materials

\footnotetext{
${ }^{3}$ At this level, they will typically be doing one 250-300-word paper about every 6 weeks.
} 
such as grammar books or online text-based grammar materials. They use Google Translate but express little confidence in its trustworthiness. Hence, in some ways, the students are in some ways skilled IT users, but don't always know what is most advantageous in a subject-specific context.

\section{STUDENT ENDLINE - DISCUSSION OF DEVELOPMENTS IN PRACTICES AND BELIEFS}

In the final questionnaire and the follow-up focus group interviews, students were asked about their changed practice and their attitudes to the new, technology-mediated way of working and its perceived effect on their work and learning processes. Questionnaire results show a marginal increase in students' beliefs that handing in papers and receiving feedback is a source of learning (90\% -> $94 \%$ ).

\subsection{The role of technology}

In the baseline interviews, the students had expressed some doubt in relation to wanting to receive feedback via the computer; they seemed to cherish the paper versions, feeling that these were more personal than what they imagined could be true of computer-mediated feedback, and those who more or less consistently also received oral feedback on their assignments felt that this was what made it personal and individualized.

However, in the endline survey, $83 \%$ of the students said that they liked the work process where they have to click their way through the feedback to correct mistakes to a high degree (40\%) or to some degree $(43 \%), 13 \%$ responding "maybe", and only $3 \%$ saying not at all. The reasons they provide in the free text answers may be condensed as relating to it being faster, easier, and more motivating to work on the computer, it providing them with an overview and forcing them to engage in deeper learning processes. Similar reasons are given in the interviews, where one student comments on the clickability/interactivity of the program:

\section{S2: Well, I think the clickability is cool.}

Interviewer: Why is it cool?

S2: Because it is like it helps you without helping you too much. You kind of get told what is wrong, and you get some suggestions. But it is still not too much help, so it's not like it corrects things for us.

In the interviews, there was also the addition that everything is now in one place, both text, feedback, and reference materials: "When it's, like, on paper, then I also have to use my phone to go use a browser, the dictionary and stuff."

In the final interviews, students elaborated on their general attitude, saying that although they thought the digital way of working was more effective, they still missed the - to them - more personal oral feedback.

\subsection{Enhanced learning}

They also claimed to have learned more (46\%) or the same (52\%) from working with their teacher's feedback on the screen, and this may be assumed to be partly related to the increased amount of time they spend working with the feedback. As illustrated in Fig.5, there appears to have been a decrease in the percentage of students who spend less than 15 minutes and a corresponding increase in the percentage who spend 15-30 minutes: 


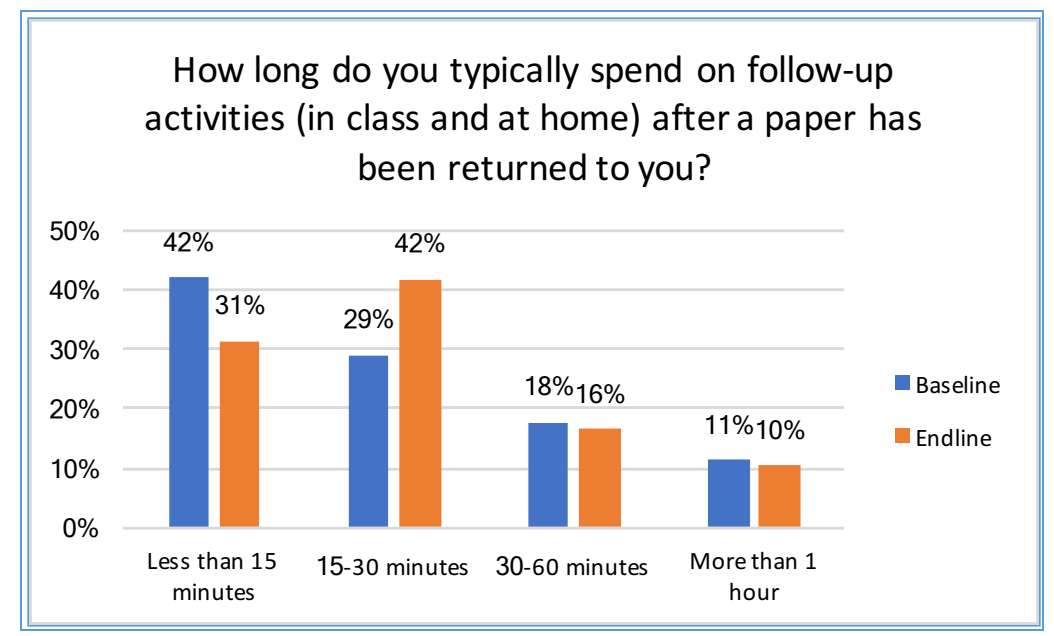

Figure 5: Comparison of amounts of time spent following up on feedback base- and endline.

One might assume, then, that the increase in the amount of time spent on revision may explain their perception of increased learning. Thus, $84 \%$ say that the revision process has been helpful to them, 61 $\%$ saying that they have learned a lot or quite a lot, $22 \%$ saying they have learnt little or nothing from it. Free text answers indicate that the responsibility, agency, problem solving approach, and personal engagement resulting from revising have been the main advantages. However, additionally, they also highlighted the clickability and the provision of more explanation as something satisfactory, e.g. because it allowed them to self-correct, being able to do something independently, not having the teacher do the corrections for them. The reasons for the increase in perceived learning outcome thus seems to rest on revision, additional time spent, and the technology used.

\subsection{Use of reference materials and teacher feedback}

Also when it comes to using reference materials, there is a marked increase in the percentages that do so frequently and a decrease in the percentage that hardly ever or never do so as illustrated in Fig. 6:

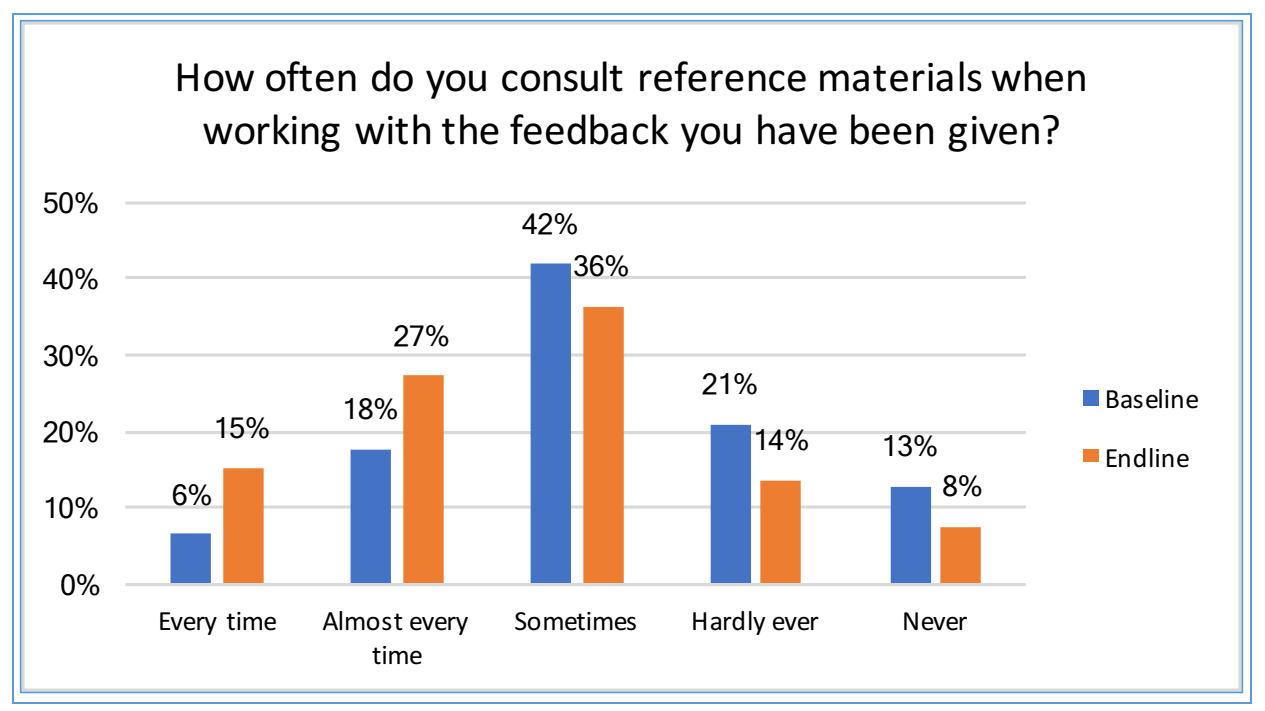

Figure 6: Comparison of uses of reference materials base- and endline.

In the endline questionnaire, students report that they do not understand quite as many of their teacher's corrections and comments as previously: $7 \%$ fewer say they understand all or almost all, $5 \%$ saying that they understand none or hardly any, but the change is hardly significant.

However, when asked directly to compare the comprehensibility of teacher feedback with technology to the paper-based, baseline use, the students predominantly express that it has become easier or is the same as illustrated in Fig. 7: 


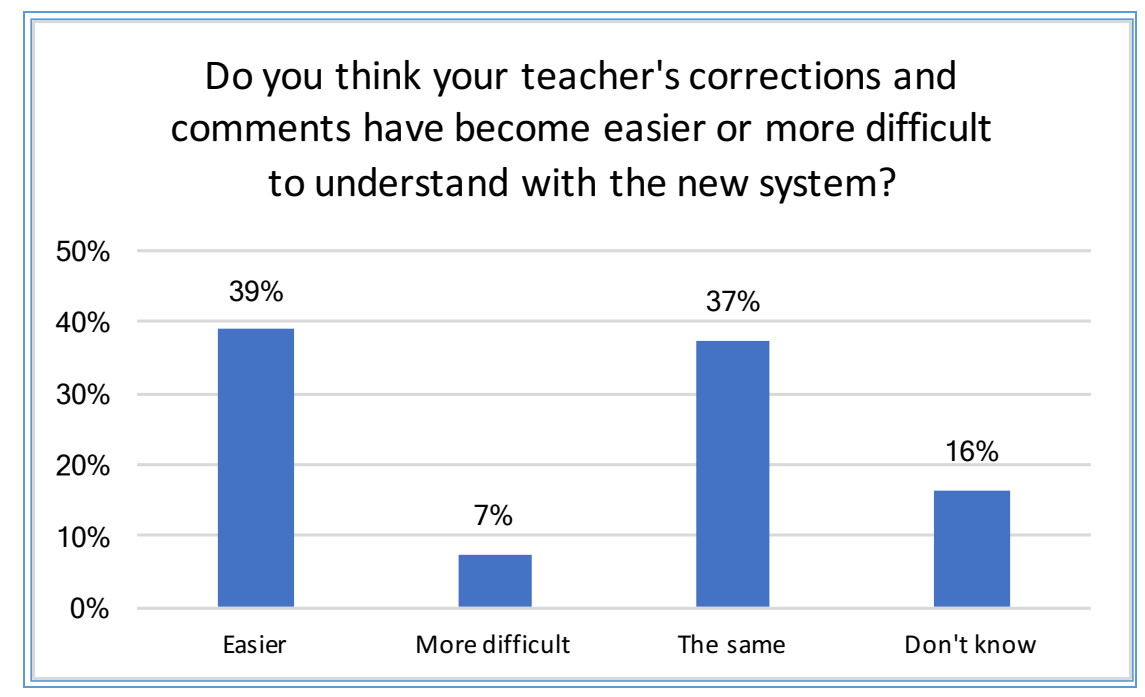

Figure 7: Student perceptions of difficulty in understanding teacher comments post-intervention.

In the free text answers, those who think it has become easier say that this is due to better explanations, involvement, legibility, recognizable error types and explanations, clarity and overview. Those who find it more difficult attribute this to the codes/categories used being too difficult to understand, explanations not being helpful, and the task being more difficult because everything is in English. Looking at these explanations, one might venture a guess that the less skilled students are experiencing difficulties as the feedback may be individualized, but the explanations and categories used were unvaried in relation to student level.

\subsection{The perceived role/influence of Markin}

In the endline interview, students indicate that the program helps create an overview in their work as not all errors are visible at once - errors can be gone through and dealt with one by one without overwhelming them. Secondly, the clickability appeals to them: Asked what they think of the highlighting feature (minus explanations), one student says that the mere highlights "are good for the kind of small mistakes you make unconsciously", and two others elaborate:

S1: I think that is good because then you can look at the word first and then you challenge yourself a little more than if you just clicked it right away or it was already shown so that you could see what was wrong.

S2: When you go over them little by little you can like...First I'll deal with this one, then I'll move on to the next one. Instead of having to have all of them visible so that in the end you are completely ... [overwhelmed].

Thus, that almost $50 \%$ of the students express that they learn more from the new way of working may be attributed to both the affordances of the program and the problem-solving that they engage in when having to revise their texts. Concerning revision, students also claim that the fact that they had to engage with the feedback and actually revise their texts is a very large contributor to their feeling of having learnt more - in combination with the program allowing them to register the error category. As expressed by two students in one of the interviews:

S1: It's kind of cool that you get something out of [writing] the paper through being able to correct your own errors and see the error types. We used to just get a grade. Then we were done with it. On to the next one! Here, we're kind of told what we need to practice and what we're good at, and if we should use different words. We need to use fancier words or ... Then you're, like, told, and that helps us in the next assignments [...] So you think about it a little more than compared to the other [previous tasks], where you just thought, 'Oh, okay, a seven, then [middle grade]. That's good.'

S2: You're more devoted to it now. You want to correct those types of error that you keep being told you make. That's kind of motivational. 'Okay, that type of error is not going to be there anymore!' 
Of course, the students also experience drawbacks in the use of technology. One major complaint is the barrier that existed at two of the schools when it came to distributing the feedback to the students, necessitating arduous work-arounds. Additionally, not all students had realized all the functions of the program, perhaps due to it being used at 5-6-week intervals and no general brush-up being given each time.

\section{CONCLUSIONS}

Several changes were implemented in the intervention, and it is not possible to directly attribute positive developments solely to the use of technology as the medium of feedback. However, there seem to be indications that the introduction of a relevant program which can scaffold teachers in providing a type of feedback that has been theoretically and empirically shown to be particularly useful may enhance students' perceived learning outcomes and entice them to apply themselves in meaningful processes, making them more positive and motivated to continue working with their written assignments.

In the study described here, we have thus seen a change in students' attitudes towards the use of technology as a mediating tool in the provision of written corrective feedback, and we have seen that they actually, after the intervention, spent more time following up on their teachers' feedback, and that they used reference materials to a higher degree.

Having feedback provided in a manner that required interaction and enabled them to self-correct along with them being required to self-correct motivated students and let them experience independence and agency.

Finally, one might argue that it would be very useful and provide students with more direction for their work if teachers were more explicit in describing and discussing the role and practices involved in written work as an important activity in the foreign language classroom.

However, further research is needed to explore these aspects of student beliefs about written corrective feedback in the foreign language classroom. 


\section{REFERENCES}

[1] M. Swain, "Communicative competence: Some roles of comprehensible input and comprehensible output in its development," Input in Second Language Acquisition, vol. 15, 1985.

[2] M. Swain, "The output hypothesis: Theory and research," in Handbook of research in second language teaching and learning, vol. 1, E. Hinkel, Ed. 2005, pp. 471-483.

[3] OECD, Students, Computers and Learning. OECD Publishing, 2015.

[4] H. W. Kjaergaard, "ICT and Feedback Practices in the Lower-Secondary Foreign Language Classroom," Journal of Educational Multimedia and Hypermedia, vol. 26, no. 2, pp. 161-177, Apr. 2017.

[5] H.-C. Liao, "Using automated writing evaluation to reduce grammar errors in writing," ELT Journal, vol. 70, no. 3, pp. 308-319, Jul. 2016.

[6] Y.-J. Wang, H.-F. Shang, and P. Briody, "Exploring the impact of using automated writing evaluation in English as a foreign language university students' writing," Computer Assisted Language Learning, vol. 26, no. 3, pp. 234-257, Jul. 2013.

[7] J. Wilson and A. Czik, "Automated essay evaluation software in English Language Arts classrooms: Effects on teacher feedback, student motivation, and writing quality," Computers \& Education, vol. 100, pp. 94-109, Sep. 2016.

[8] E. Macaro, Z. Handley, and C. Walter, "A systematic review of CALL in English as a second language: Focus on primary and secondary education," Language Teaching, vol. 45, no. 1, pp. 143, Jan. 2012.

[9] R. Stannard, "The spelling mistake: Scene one, take one," Times Higher Education (THE), 08Dec-2006. [Online]. Available: https://www.timeshighereducation.com/features/the-spellingmistake-scene-one-take-one/207117.article. [Accessed: 12-Dec-2016].

[10] R. Stannard, "Goodbye to lecture notes," Russell Stannard on technology in the lecture theatre | Education I The Guardian, Sep-2007. [Online]. Available: https://www.theguardian.com/education/2007/sep/18/link.link24. [Accessed: 15-Dec-2016].

[11] R. Stannard, "Talking feedback," the Guardian, 10-Jan-2012. [Online]. Available: http://www.theguardian.com/education/2012/jan/10/esl-video-feedback. [Accessed: 15-Dec2016].

[12] R. Stannard, "Is this the start of a feedback revolution? How Technology could change the way we provide feedback," The European Journal Of Applied Linguistics and TEFL, vol. 3, no. 2, pp. 13-26, 2014.

[13] R. Stannard, "How To Use Technology To Provide Feedback," EFL Magazine, 11-Dec-2015. .

[14] R. Stannard, "A genuine revolution in providing feedback to students on their written work," AngloFiles, no. 182, pp. 88-91, Nov. 2016.

[15] R. Thompson and M. J. Lee, "Talking with Students through Screencasting: Experimentations with Video Feedback to Improve Student Learning," The Journal of Interactive Technology \& Pedagogy, no. 1, 2012.

[16] B. Brick and J. Holmes, "Using screen capture software for student feedback: towards a methodology," in IADIS International Conference on Cognition and Exploratory Learning in the Digital Age, 2008.

[17] F. Harper, H. Green, and M. Fernandez-Toro, "Evaluating the integration of Jing ${ }^{\circledR}$ screencasts in feedback on written assignments," in Interactive Collaborative Learning (ICL), 2012 15th International Conference on, 2012, pp. 1-7.

[18] J. Séror, "Show Me! Enhanced Feedback through Screencasting Technology.," TESL Canada Journal, vol. 30, no. 1, pp. 104-116, 2012.

[19] P. Mathisen, "Video feedback in higher education-a contribution to improving the quality of written feedback," Nordic Journal of Digital Literacy, vol. 7, no. 02, pp. 97-113, 2012. 
[20] M. L. Silva, "Camtasia in the Classroom: Student Attitudes and Preferences for Video Commentary or Microsoft Word Comments During the Revision Process," Computers and Composition, vol. 29, no. 1, pp. 1-22, Mar. 2012.

[21] S. Hepplestone, G. Holden, B. Irwin, H. J. Parkin, and L. Thorpe, "Using technology to encourage student engagement with feedback: a literature review," Research in Learning Technology, vol. 19, no. 2, pp. 117-127, Jul. 2011.

[22] R. Stannard, "A New Direction in Feedback," Humanising Language Teaching Magazine for teachers and teacher trainers, vol. 10, no. 6, Dec. 2008.

[23] J. Nieminen, KungFu Writing. Helsinki: FINNED OY, 2016.

[24] A. Molander, LangCorr. Fredericia: LangCorr, 2016.

[25] GradeMark. Oakland, CA: Turnitin, 2016.

[26] M. Holmes, Markin. Creative Technology, 2009.

[27] EasyCorrect. Frederiksberg: EasyCorrect.

[28] R. Ellis, "A typology of written corrective feedback types," ELT Journal, vol. 63, no. 2, pp. 97-107, May 2008.

[29] J. Bitchener and U. Knoch, "Raising the linguistic accuracy level of advanced L2 writers with written corrective feedback," Journal of Second Language Writing, vol. 19, no. 4, pp. 207-217, Dec. 2010.

[30] R. Ellis, S. Loewen, and R. Erlam, "Implicit and explicit corrective feedback and the acquisition of L2 grammar," Studies in Second Language Acquisition, vol. 28, no. 2, pp. 339-368, Jun. 2006.

[31] S.-W. Yeh and J.-J. Lo, "Using online annotations to support error correction and corrective feedback," Computers \& Education, vol. 52, no. 4, pp. 882-892, Maj 2009.

[32] T. Depieri, "The effects of using correction codes and redrafting on intermediate students' writing," Cambridge English: Research Notes, no. 61, pp. 15-25, Aug. 2015.

[33] M. Elicker and U. Fürstenberg, "Feedback in Student Writing: A Closer Look at Code-Marking," in Feedback matters: Current feedback practices in the EFL classroom, M. Reitbauer, C. Campbell, S. Mercer, J. Fauster, and R. Vaupetisch, Eds. Peter Lang, 2013.

[34] J. F. Lalande, "Reducing Composition Errors: An Experiment," The Modern Language Journal, vol. 66, no. 2, pp. 140-149, 1982.

[35] M. Schulze, "Grammatical errors and feedback: Some theoretical insights," CALICO Journal, pp. 437-450, 2003.

[36] C. A. Chapelle, "Computer assisted language learning," in The Handbook of Educational Linguistics, B. Spolski and F. Hult, Eds. Wiley Online Library, 2008, pp. 585-595.

[37] J.-T. Pujolà, "Did CALL feedback feed back? Researching learners' use of feedback," ReCALL, vol. 13, no. 01, May 2001. 